This item was submitted to Loughborough's Research Repository by the author.

Items in Figshare are protected by copyright, with all rights reserved, unless otherwise indicated.

\title{
Development of a full scale experimental and simulation tool for environmental control system optimisation and fault detection
}

\section{PLEASE CITE THE PUBLISHED VERSION}

http://dx.doi.org/10.2514/6.2015-1196

\section{PUBLISHER}

(C) American Institute of Aeronautics and Astronautics

\section{VERSION}

AM (Accepted Manuscript)

\section{PUBLISHER STATEMENT}

This work is made available according to the conditions of the Creative Commons Attribution-NonCommercialNoDerivatives 4.0 International (CC BY-NC-ND 4.0) licence. Full details of this licence are available at: https://creativecommons.org/licenses/by-nc-nd/4.0/

\section{LICENCE}

CC BY-NC-ND 4.0

\section{REPOSITORY RECORD}

Childs, Thomas, Andy Jones, Rui Chen, and Angus Murray. 2016. "Development of a Full Scale Experimental and Simulation Tool for Environmental Control System Optimisation and Fault Detection". figshare. https://hdl.handle.net/2134/20134. 


\title{
Development of Full Scale Experimental and Simulation Tool for Environmental Control System Optimisation and Fault Detection
}

\author{
Thomas Childs ${ }^{1}$, Andy Jones ${ }^{1}$, Prof. Rui Chen ${ }^{1 *}$ and Angus Murray ${ }^{2}$
}

\begin{abstract}
This paper documents the installation of a fast-jet military aircraft Environmental Control System (ECS) ground test facility. The system used in this case is a bleed-air driven two-wheel bootstrap cycle with low pressure water extraction. The facility allows the ECS to be run at conditions similar to those in the aircraft during ground operation. Data from the rig is presented and used to validate a 1-D thermodynamic model. The relationships between aircraft altitude and speed against ECS Coefficient of Performance and system heat rejection are presented, seamlessly utilising both experimental and modelled data. Furthermore, a scenario depicting a ram air blockage in the secondary heat exchanger demonstrates the system's ability to mask faults. The physical system is used for componentlevel analysis, whilst the model extends this to system-level. General attributes of the system operation are discussed.
\end{abstract}

$\begin{array}{ll}\text { APU } & \text { Auxiliary Power Unit } \\ \text { CAU } & \text { Cold Air Unit } \\ \text { CoP } & \text { Coefficient of Performance } \\ \text { ECS } & \text { Environmental Control System } \\ \text { FDI } & \text { Fault Detection and Isolation } \\ \text { GTF } & \text { Ground Test Facility } \\ \text { HT } & \text { Heat Transfer } \\ \text { HX } & \text { Heat Exchanger } \\ \text { ISA } & \text { International Standard Atmosphere } \\ \text { LRI } & \text { Line-Replaceable Item } \\ \text { MF } & \text { Mass Flow } \\ \text { PID } & \text { Proportional-Integral-Differential } \\ \text { PR } & \text { Pressure Ratio } \\ \text { TCV } & \text { Temperature Control Valve } \\ \text { ETCV } & \text { Equipment TCV } \\ \text { CTCV } & \text { Cabin TCV }\end{array}$

Nomenclature
\begin{tabular}{ll}
$\eta$ & Efficiency \\
$C$ & Fluid Velocity \\
$c_{p}$ & Specific Heat Capacity / Constant Pressure \\
$c_{v}$ & \multicolumn{1}{c}{ / Constant Volume } \\
$\gamma$ & Polytropic Coefficient \\
$h$ & Enthalpy \\
$\dot{m}$ & Mass Flow \\
$P$ & Pressure \\
$Q / \dot{Q}$ & Heat Energy / Flow \\
$R$ & Universal Gas Constant \\
$T$ & Temperature \\
$\dot{W}$ & Work
\end{tabular}

\section{Introduction}

$\mathrm{T}^{\mathrm{H}}$ HE thermal heat loads on-board a fast-jet military aircraft are conditioned by the Environmental Control System (ECS). Typically the ECS requires a high demand of bleed and ram air for cooling applications; reducing engine performance, increasing fuel consumption and aerodynamic $\mathrm{drag}^{1}$. In order to increase aircraft performance and efficiency, bleed and ram air use must be minimised ${ }^{2,3}$.

Perfect full scale physical testing of ECS is impossible to achieve when considering real world constraints such as space, funding and time ${ }^{4}$. Ground test facilities require substantial infrastructure in order to generate ram and bleed air supplies fully representative of in-flight conditions. Airborne testing is an expensive and time consuming process; due to the requirements of aircraft recertification for on-board test equipment and difficulties associated with full scale aircraft operation. ECS modelling is well documented, but not so well validated due to the aforementioned difficulties ${ }^{5-8}$.

\footnotetext{
${ }^{1}$ Loughborough University, Leicestershire, UK

* Correspondence address: R.Chen@lboro.ac.uk

${ }^{2}$ BAE Systems Military Air \& Information, Warton, Lancashire, UK
} 
A significant proportion of aircraft downtime can be attributed to ECS issues. Bleed air components often require unscheduled maintenance due to operating in extreme conditions. Coalescer elements in low-pressure water extractors require regular replacement. Aircraft downtime due to air cycle ECS failures and maintenance is reported of the order 1-5k hours per 10k flight hours 9 .

For these reasons, the requirement for a new Ground Test Facility (GTF) was identified. The aim is to provide selective flight case replication on genuine aircraft equipment, the performance of which is then artificially extended by means of an integrated thermodynamic simulation. The ECS is housed in a test cell and can be run for extended periods of time, simulating both steady-state and transient operation. Data from these tests is used to further the understanding of the system and its associated complexities.

The performance of the system is assessed by means of absolute bleed air heat transfer (system power) and Coefficient of Performance (CoP) (system efficiency). For GTF operation, input power for CoP is calculated by ideal isentropic compression and heating laws. This allows any infrastructure efficiencies to be ignored. In order to compare the GTF results to those of the simulation tool, the same procedure is used to calculate CoP at altitude (ignoring engine inefficiencies). Compression and heating power are taken from atmospheric conditions according to International Standard Atmosphere (ISA) standard day ${ }^{1}$, in both cases.

\section{Ground Test Facility - Complete Fast-Jet ECS Rig}

The ECS utilised for this task was formerly installed in a BAE Systems Hawk Advanced Jet Trainer aircraft. The system uses a bleed-air driven two-wheel bootstrap cycle, with low-pressure water extraction. Pack exhaust temperature is controlled by two independent bypass branches with PID-controlled servo valves. The feed for each bypass is taken upstream of the precooler. The two possible airflow paths are referred to as the 'cycle' and 'bypass' flow throughout this report. For energy analysis purposes, these two gas paths are treated independently.

The donor aircraft has no vapour- or liquid-cycle cooled subsystems; therefore no heat exchangers other than the two concerned with bleed air cooling are present. A schematic of the ECS in its experimental setup is shown in Figure 1, and a photograph of the installation in Figure 2. The donor aircraft has the ability to utilise bleed air from either the engine or the Auxiliary Power Unit (APU).

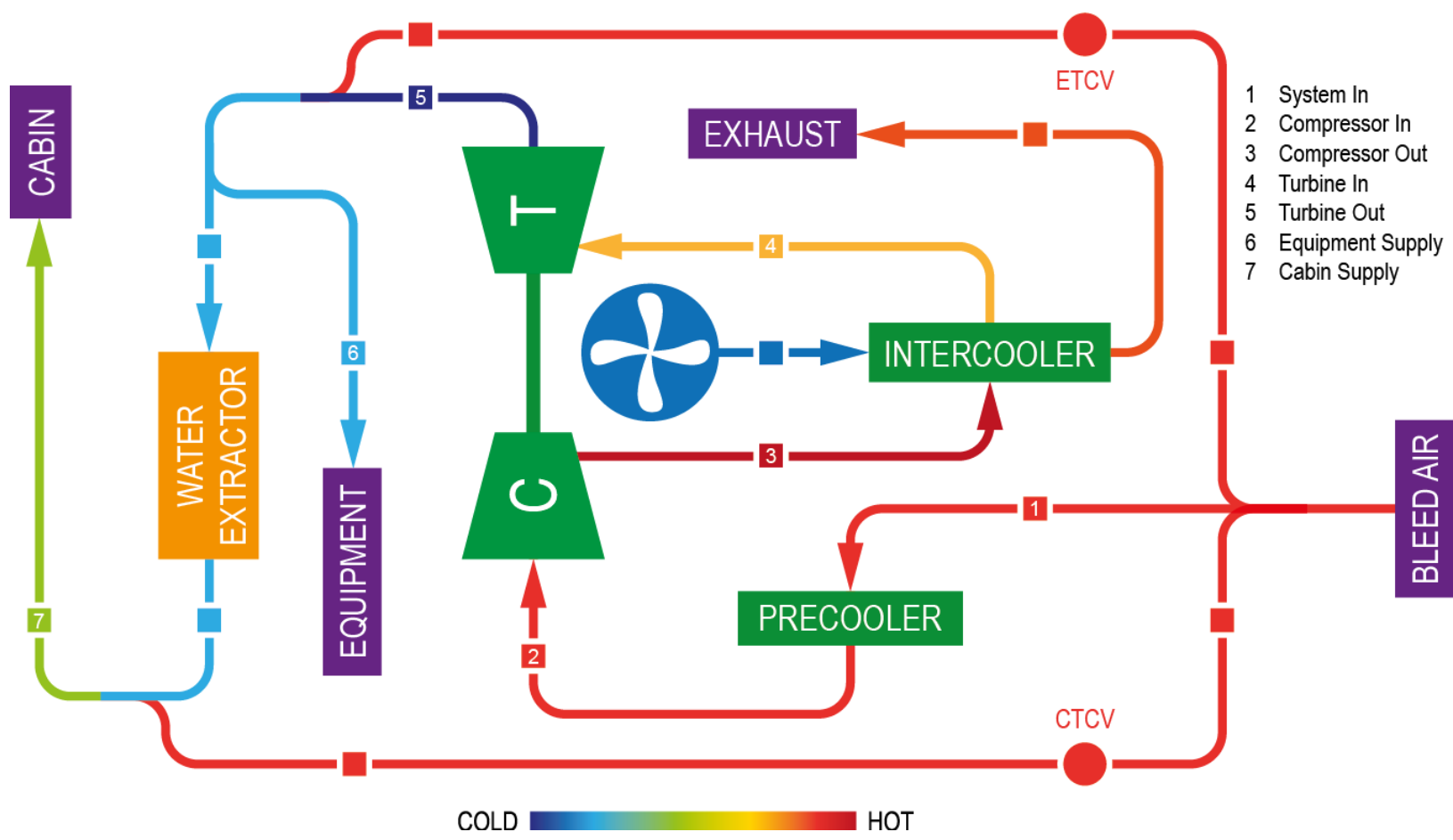

Figure 1. ECS Schematic \& Instrumentation List where instrumentation locations (temperature \& pressure) are denoted by square nodes on the bleed air path. The numbered nodes are those referred to in this report. Note that no ram air flows through the precooler in this experimental setup. The colour of the bleed air path is representative of its temperature. 


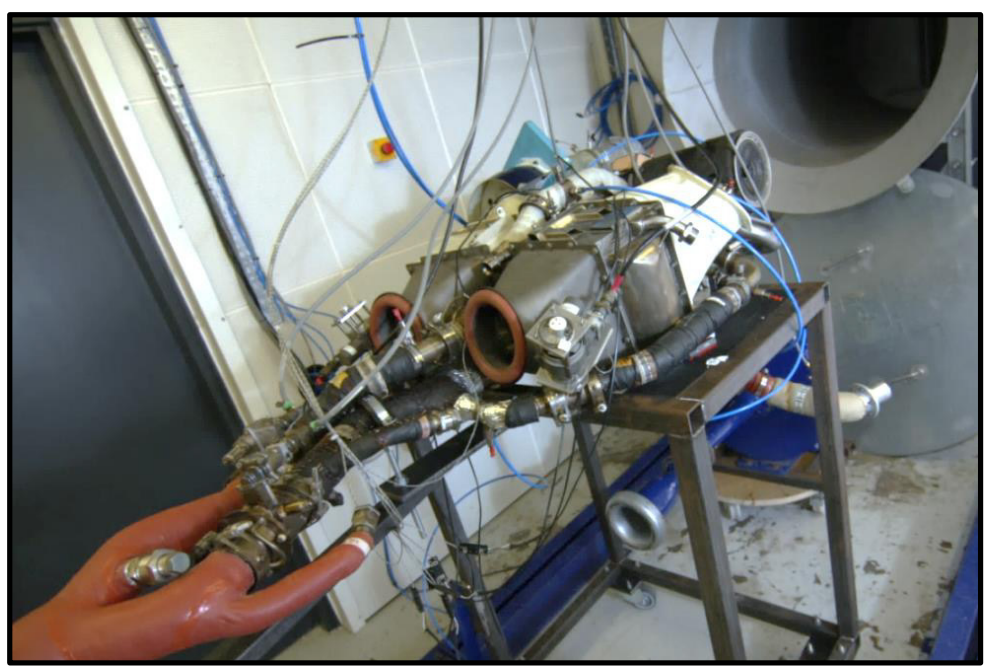

Figure 2. ECS Rig Installation
The benefits of using this type of cycle in a small trainer aircraft are simplicity (pertaining to minimal aircraft down-time through failure), small overall dimensions (to facilitate compact packaging), and low mass (to benefit vehicle manoeuvrability and specific power $)^{10}$. Issues arise, however, when the performance limits of such a system are met. Efficiency gains are required in order to increase cooling capacity, when increases in bleed air consumption are not viable.

The air delivery system for the GTF is specified to meet refrigeration cycle (compressor) inlet conditions. This is to avoid excessive cost and energy consumption associated with generating engine tapping conditions. The majority of this energy would be lost across the precooler and bypass branches. The performance of the precooler is simple to model, and not investigated in this report. Table 1 shows the specification of the air delivery system.

The rig is instrumented for temperature and pressure before and after each component in the bleed air path; in addition to system inlet, exhaust and ram air temperatures. Bleed air mass flow is measured by means of an orifice plate. Ram air mass flow is measured from a differential pressure across a bellmouth inlet (visible in Figure 2). Both temperature control valves (TCVs) are instrumented for position.

The ECS is driven via a genuine cockpit control panel and associated electronics. This allows both manual and automated control of the TCVs and air distribution valves.

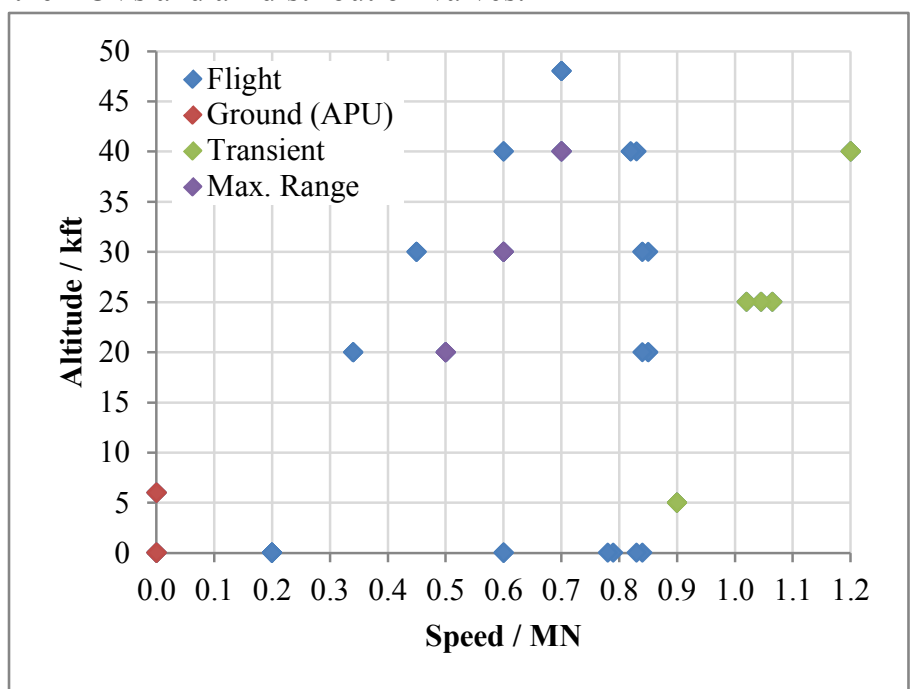

Figure 3. Hawk Flight Envelope used as input to $1 D$ model

Table 1. GTF Air Supply Specification
\begin{tabular}{|l|l|l|}
\hline Requirement & Method & Specification \\
\hline \multirow{2}{*}{$\begin{array}{l}\text { Bleed air } \\
\text { pressure }\end{array}$} & $\begin{array}{l}\text { Positive-displacement } \\
\text { compressor }\end{array}$ & $368 \mathrm{~kW}$ \\
\cline { 2 - 3 } & Receiver tanks & $40 \mathrm{~m}^{3} @ 14 \mathrm{Bar}$ \\
\hline Bleed air temp. & Electric process air heater & $6 \mathrm{~kW}$ \\
\hline Ram air flow & Centrifugal blower & $\begin{array}{l}0.1 \mathrm{kgs}^{-1} @ 1 \\
\mathrm{kPa}\end{array}$ \\
\hline Ram air temp. & $\begin{array}{l}\text { Equivalent cooling } \\
\text { Ram air heat transfer calculated independent } \\
\text { of temperature }\end{array}$ \\
\hline Run time & Worst case scenario & 54 mins \\
\hline
\end{tabular}

The aim of the GTF is to generate sufficient data to validate performance of the onedimensional thermodynamic simulation; and to allow analysis of the control system under transient conditions. Also, performance of the more complex components in the system (principally the Cold Air Unit (CAU)) can be modelled empirically, saving time and uncertainty.

The rig is a particularly powerful tool for its ability to validate new components and technologies with minimal risk and expense, when compared to a flight test. The GTF does have limitations, but these can be easily overcome in a modelling environment. The infrastructure will be improved upon in the future, to improve the proportion of the flight envelope that can be covered by the GTF. 


\section{One-Dimensional Thermodynamic Simulation}

The primary objective of the GTF is to assess component-level performance of the refrigeration cycle. Inlet condition generation is limited, and exhaust conditions cannot be driven. In order to fully evaluate the performance of the ECS at system-level, a full system model was devised. This is capable of simulating entire flight profiles at altitude, for a more accurate measure of overall system performance. The model is built in MSC Easy5.

The model is able to simulate engine and cabin conditions at a range of altitudes and speeds, as per the aircraft's flight envelope (shown in Figure 3). Simulation cases are concerned with the extremes of this envelope, as these are the conditions where the system is under the highest load.

The model performance is validated against the rig at ground case conditions. Model output data is limited to system-level performance, due to the complexities involved with mapping turbomachinery. The model has a tendency to over-predict cycle performance (due to non-linearities in the real system), however exhaust conditions are accurate. This only affects energy flow analysis between the components, rather than overall bleed air heat extraction. Model accuracy is on average: $4.6 \%$ error pre-cycle, $13.2 \%$ error mid-cycle, $4.7 \%$ error post-cycle.

Figure 4 shows a schematic of the model. Each functional block is explained in Table 2 . The model is governed by open system mass flow continuity equations. The turbomachinery (CAU) is modelled according to isentropic compression and expansion laws. Flow in other parts of the system, including the heat exchangers, is adiabatic. Provision to calculate heat transfer to ambient through pipe lagging, etc., is included in both the rig (through instrumentation locations) and the model but has an insignificant effect on system-level performance. The equations upon which the model is based are reproduced below ${ }^{11}$.

$$
\begin{array}{ll}
\text { Isentropic Open System Heat / Work Transfer: } & \dot{Q}+\dot{W}=\dot{m}\left[\left(h_{2}-h_{1}\right)+\frac{1}{2}\left(C_{2}^{2}-C_{1}^{2}\right)\right] \\
\text { Isentropic Compression in Turbomachinery: } & T_{2}-T_{1}=\frac{T_{1}}{\eta}\left[\left(\frac{P_{2}}{P_{1}}\right)^{\frac{\gamma-1}{\gamma}}-1\right] \\
\text { Heat Exchanger Core Heat Transfer: } & Q=\eta_{H X} c_{p_{\text {min }}}\left(T_{H_{\text {in }}}-T_{C_{\text {in }}}\right)
\end{array}
$$

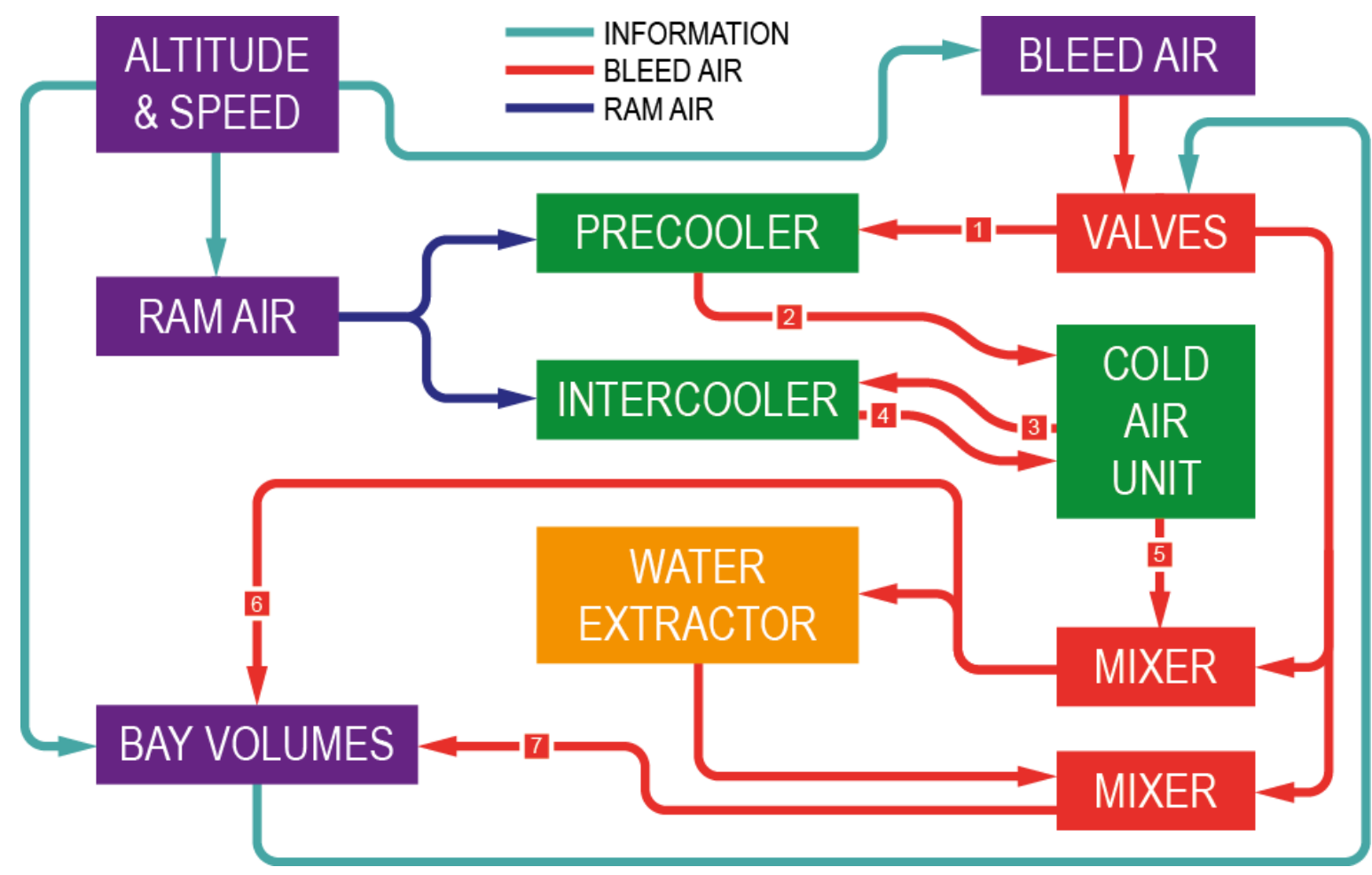

Figure 4. ECS 1D Model Schematic where instrumentation locations are numbered as in Figure 1. 
Table 2. 1D Thermodynamic Modelling Strategy

\begin{tabular}{|l|l|l|}
\hline Functional Area & Modelling Method & Validation Notes \\
\hline Bleed Air Model & $\begin{array}{l}\text { Boundary pressure and temperature specified } \\
\text { from engine \& APU performance data. } \\
\text { Aircraft altitude \& speed data used to look- } \\
\text { up ambient conditions. }\end{array}$ & $\begin{array}{l}\text { Same inlet conditions as GTF in order to } \\
\text { validate model performance. }\end{array}$ \\
\hline $\begin{array}{l}\text { Precooler } \\
\text { Intercooler }\end{array}$ & $\begin{array}{l}\text { Ram air flow driven by stagnation pressure, } \\
\text { calculated from vehicle speed and duct } \\
\text { geometry. Heat transfer rate calculated by } \\
\text { Easy5 after specifying cooler geometry. }\end{array}$ & $\begin{array}{l}\text { Heat transfer efficiency given according to } \\
\text { generic map and tuned according to } \\
\text { standalone physical test. Heat transfer areas } \\
\text { estimated. }\end{array}$ \\
\hline Cold Air Unit & $\begin{array}{l}\text { Radial-flow compressor \& turbine linked by } \\
\text { shaft transmitting power \& speed. Pre-coded } \\
\text { blocks within Easy5 assuming isentropic } \\
\text { compression laws. }\end{array}$ & $\begin{array}{l}\text { Efficiency \& pressure ratios given by look-up } \\
\text { maps derived from generic radial machines. } \\
\text { Internal geometries are estimated. Validated } \\
\text { to GTF by back-pressure balancing and shaft } \\
\text { power transmission efficiency. }\end{array}$ \\
\hline Bypass Valves & $\begin{array}{l}\text { PID control integral to Easy5, valve flow coefficients estimated according to geometry. Inputs } \\
\text { for PID control taken from bay volume temperatures. Manual valve override available. }\end{array}$ \\
\hline Flow Mixers & $\begin{array}{l}\text { Node volumes fed by orifices of correct } \\
\text { relative geometry. }\end{array}$ & $\begin{array}{l}\text { Node exhaust temperature validated to GTF } \\
\text { by modification of model orifices. }\end{array}$ \\
\hline Bay Volumes & $\begin{array}{l}\text { Large volumes that approximate those of the cabin \& equipment bays. Internal flow routing } \\
\text { mimics that of the aircraft. Model bay volume pressure controlled to aircraft cabin } \\
\text { pressurisation schedule through variable exhaust orifice. }\end{array}$ \\
\hline
\end{tabular}

\section{Performance Results and Findings}

\section{A. Non-Measured Parameter Calculation}

In order to introduce a degree of normalisation across the results from GTF and model, standardised methods of assessing system performance were devised. Heat rejection of the whole system (from bleed air inlet to system exhaust) depicts system performance. Coefficient of Performance $(\mathrm{CoP})$ calculates this heat rejection relative to the energy required to generate the inlet conditions. Cycle mass flow is mapped relative to compressor inlet pressure, for the calculation of work and heat transfer within the cycle.

System heat rejection is calculated according to the difference between bleed air inlet temperature and system exhaust temperature. The exhaust temperature is averaged between the equipment and cabin supplies according to the mass flow split between the two. Heat rejection rate $\dot{Q}=\dot{m} c_{v} \Delta T$

Coefficient of Performance relates this heat rejection rate to the work required to compress and heat the bleed air from atmospheric conditions. This is calculated according to ideal gas laws and the governing equations used for modelling. Coefficient of Performance $C o P=\frac{Q_{\text {out }}}{W_{\text {in }}}$

\section{B. General System Performance with respect to Bleed Air Minimisation (Measured Data)}

Figure 5 and Figure 6 show the response to an inlet pressure sweep, where inlet temperature and cabin demand temperature are held constant. The TCVs open with increasing inlet pressure (lines with markers, Figure 5), allowing the system to achieve constant cabin supply temperature. Note that turbine exhaust temperature remains constant despite increasing turbine inlet temperatures (dashed lines, Figure 6). This is due to refrigeration cycle performance increasing with inlet pressure, where higher turbine expansion ratios lead to lower turbine exhaust temperatures. The bypass flows work to counteract this by two methods: one is to mix the cold post-cycle air with warm bleed air; the other is to alter the back-pressure of the system, essentially throttling the cycle.

Increasing the amount of bypass flow required to obtain a temperature reduces the system's CoP, due to the inefficient nature of the bypass flows. This test is designed to simulate a common operational requirement of the system: where cooling load is constant but inlet conditions vary. It indicates the versatility of the system, but also its potential to operate at reduced efficiency. Higher inlet pressures may lead to higher refrigeration cycle performance, but at the expense of system efficiency. 


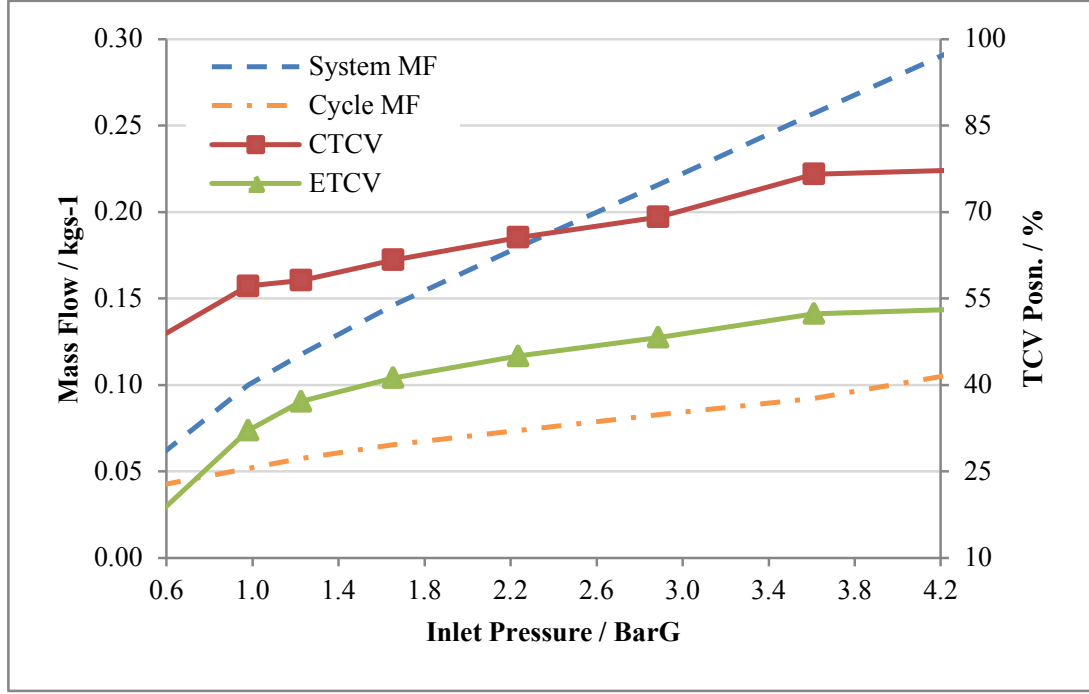

Figure 5. Bypass Response to Pressure Sweep

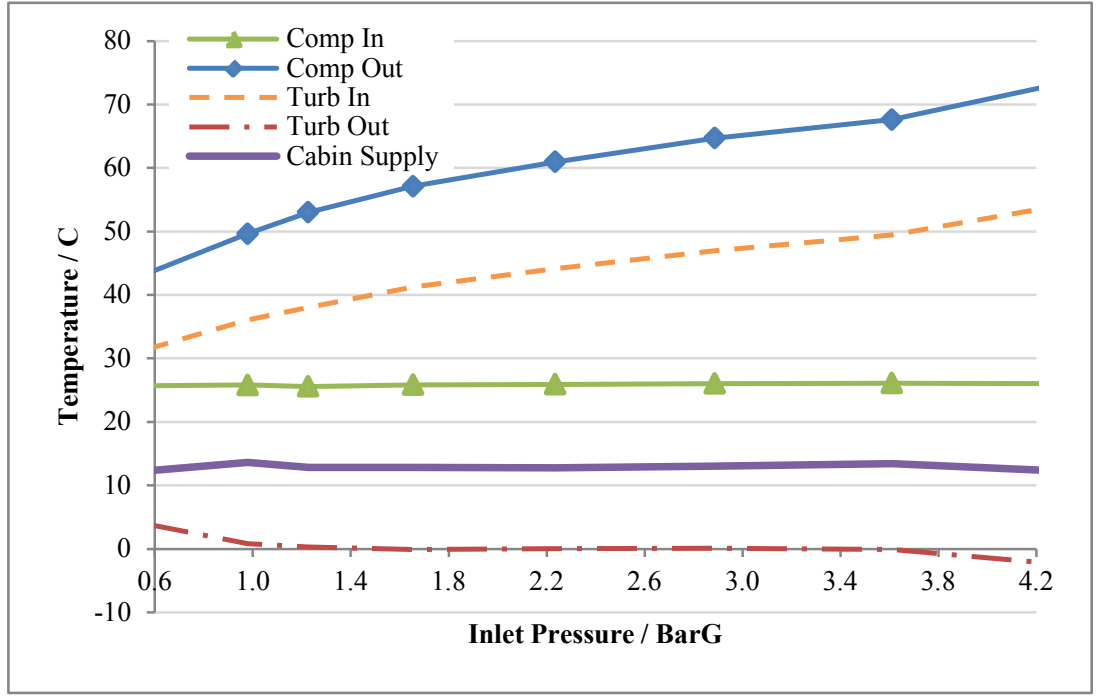

Figure 6. Temperature Response to Pressure Sweep

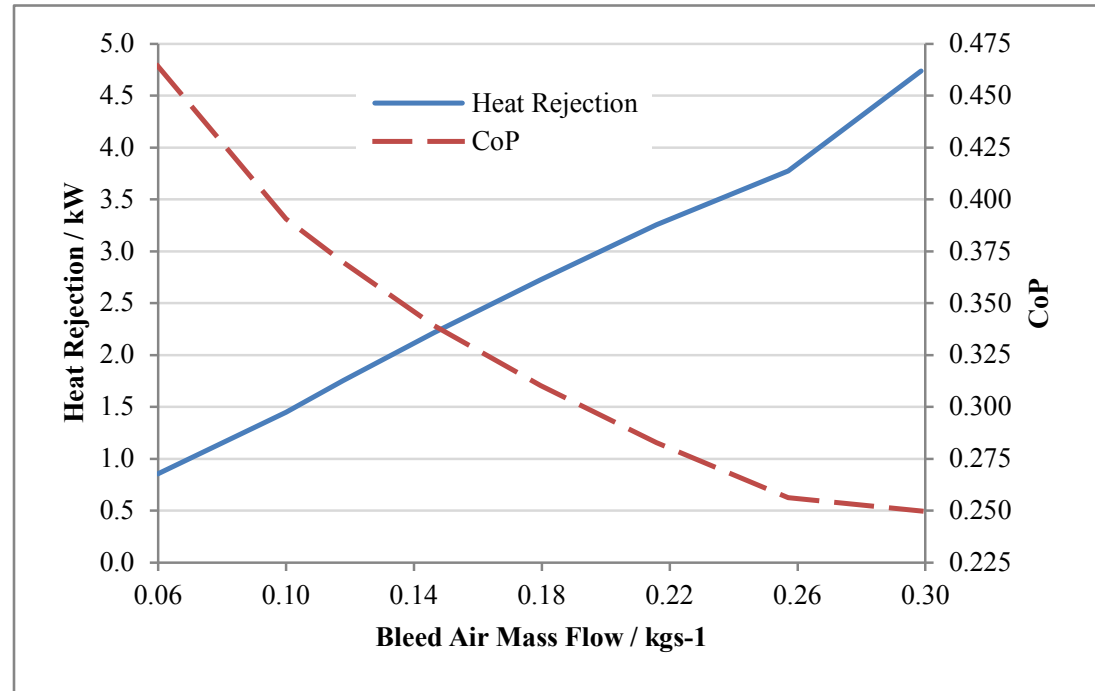

Figure 7. System Efficiency against Mass Flow
Figure 7 shows system heat rejection and $\mathrm{CoP}$ against bleed air mass flow for the same inlet pressure sweep. Whilst system power (and hence cooling ability) increases with bleed air consumption, system efficiency falls on a curve. This indicates the possibility of optimisation, however this system analysis does not include the performance of any downstream components such as canopy demist ducts or force-cooled LRIs. In this instance, CoP indicates the loss of thrust that the aircraft must overcome per unit of cooling performance. The efficiency gains of reducing bleed air consumption, for this system, are twofold: reduced net load on the engine is accompanied by more efficient operation of the ECS.

\section{Control System Complexities (Measured Data)}

Figure 8 below illustrates one of the benefits of testing the real system rather than relying entirely on simulated data. The two lines represent bleed air temperature throughout the refrigeration cycle, for two different scenarios with identical bleed and ram air inlet conditions. This scenario would most likely be caused by diving to an altitude as opposed to climbing to the same altitude. It would be prohibitively difficult to simulate this response.

As a result, the two operating points are achieved with different TCV positions but with a similar overall level of cycle bypass. State 2 is both working the cycle harder and using more bypass, to achieve the same cabin temperature output as State 1. This means that whilst the system is delivering more performance in State 2 (higher CoP, cycle efficiency and heat rejection), it is at the expense of increased bypass flow. This indicates that the control system is not optimised for peak efficiency. Also note that State 2 uses more bypass flow and has a higher CoP than State 1, which is

American Institute of Aeronautics and Astronautics 
contrary to the evidence presented in the previous section (Figure 7).

It is evident that the control system sacrifices equipment supply temperature to prioritise cabin temperature in many of the results displayed here. Although the equipment supply branch contributes a small proportion of the overall mass flow, driving the refrigeration cycle to lower temperatures for the same cabin temperature demand has the effect of increasing the air path entropy (a measure of the working fluid's energy which is unavailable for conversion to useful work). This could also lead to over-cooling of the avionics in some scenarios.

This phenomenon highlights the complexity of what is only a simple ECS. There are essentially an infinite number of ways to produce the same exhaust conditions, each with different associated efficiencies. This particular problem is unique to this system and its own allowable settled error, but the observation is still valid.

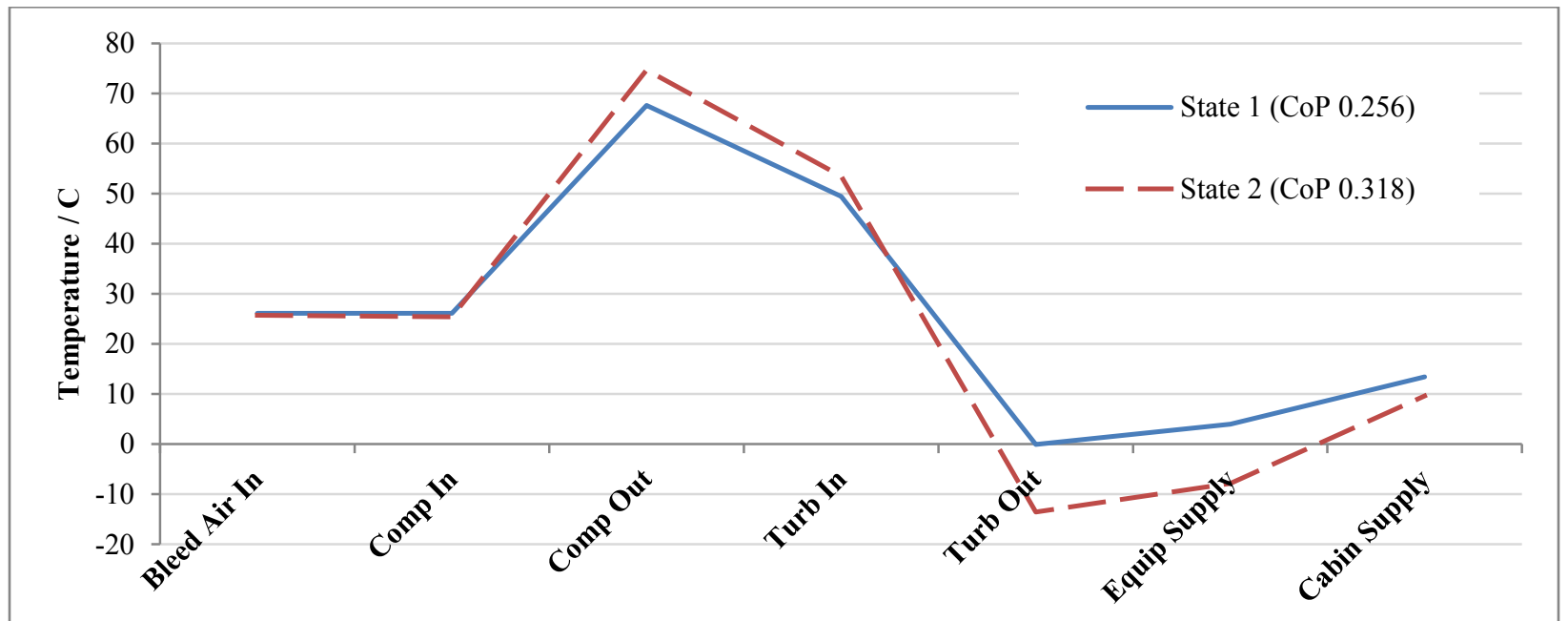

Figure 8. Refrigeration Cycle Temperature shown for two differing cycles at the same inlet conditions and cabin temperature demand. The red state simultaneously works the cycle harder than the blue state, whilst using more bypass flow to increase the temperature to the demanded level.

\section{Performance Linearity and Input Correlation (Measured \& Modelled Data)}

In order to validate the thermodynamic modelling exercise, the rig was run through independent sweeps of one control variable. This was performed under manual valve position control. The results of many of these tests yielded linear relationships, such as the one used for calculating cycle mass flow proportion. Figure 9 shows how CAU pressure ratio varies linearly with cycle inlet pressure. This data is collected over many tests with varying levels of bypass flow. This relationship is always true, and is used to calculate cycle mass flow proportion.

The following graphs (Figure 10) show the response, in terms of $\mathrm{CoP}$, for several different parameters. These plots are extended beyond the limitations of the current air delivery system by the validated thermodynamic model.

The data in each plot is segregated into three categories: blue points are modelled flight conditions, red points are modelled ground

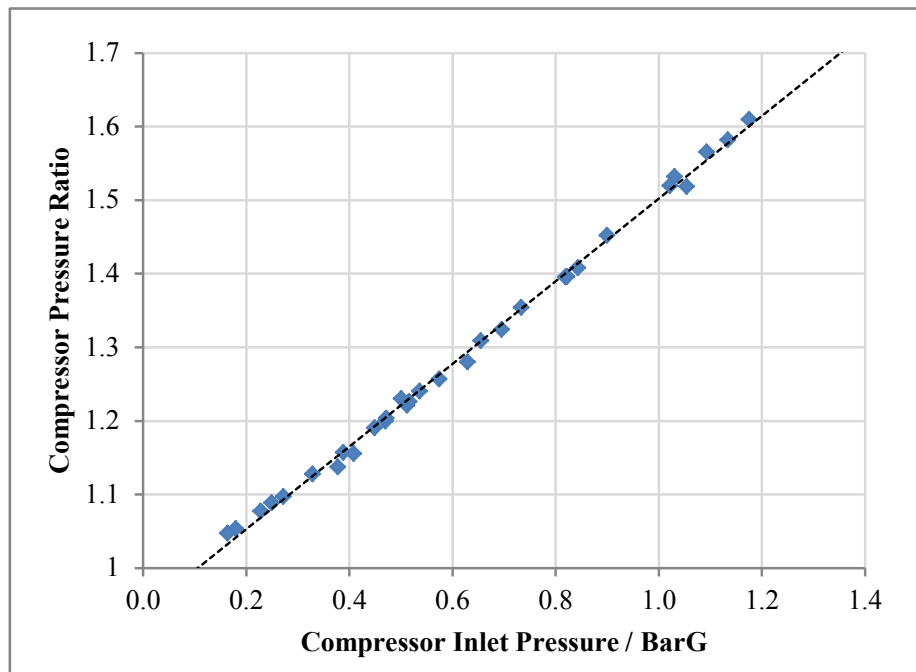

Figure 9. CAU Pressure Ratio shown across differing levels of bypass flow cases (where the ECS takes its bleed air supply from the APU), and green points are physical data taken from the rig. The results shown here, whilst not totally linear, each exhibit a strong correlation for CoP. These parameters would be the most beneficial to interrogate for any potential efficiency gains in the system. 
The performance of the CAU is governed by its pressure ratio. Higher inlet pressures yield higher pressure ratios which yield higher shaft power. Cycle inlet pressure is independent of exhaust (cabin) pressure, therefore higher inlet pressures yield higher refrigeration cycle efficiencies.

Higher bleed air inlet temperatures drive the heat transfer in the heat exchangers more effectively, due to higher differential temperatures between bleed air and ram air. As can be seen from Figure 10d), intercooler heat transfer is a strong contributor to CoP. The graphs in a) and d) together confirm that heat exchanger performance is paramount for good cycle efficiency, whilst other tests have shown that compressor inlet temperature has a lesser effect on compressor performance. To add to this, entropy change across the heat exchangers is low compared to the compressor and turbine due to the relatively low pressure drop. Inlet temperature drives heat exchanger performance, whilst inlet pressure drives CAU performance.

Bypass flow affects CoP because of the wasteful nature by which it is discharged. The work done to compress the air is lost to pipe head pressure, where energy recovery opportunities are limited. The main effect of increased bypass flow is increased system mass flow, which can be beneficial in some cases. The GTF data is acquired at high bypass flows due to the low bleed air temperature at inlet.

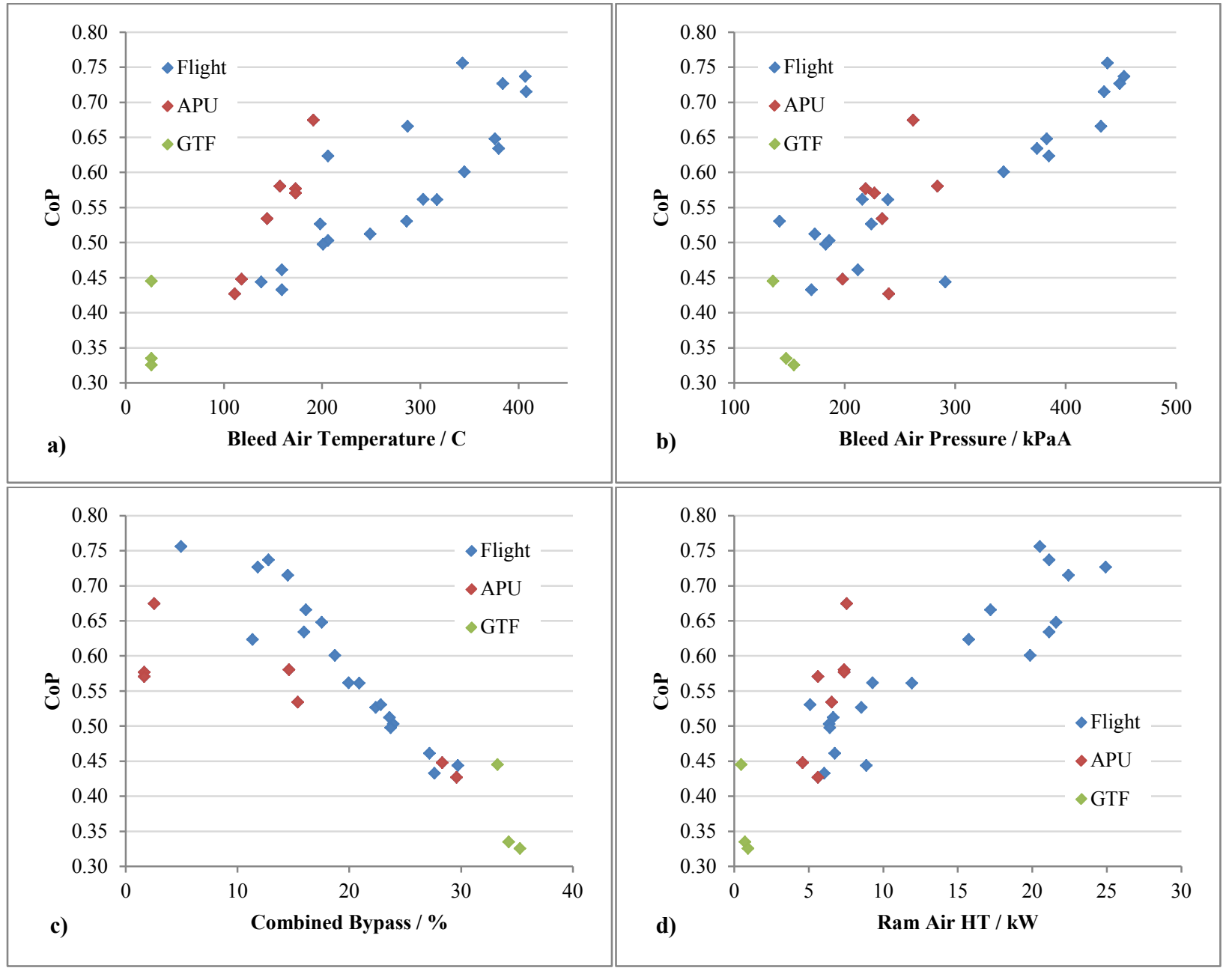

Figure 10. CoP Shown against Several System Parameters

\section{E. Altitude Effects (Modelled Data)}

The cabin demand is generally varied according to ambient conditions. High ambient temperatures require low temperature demand and vice-versa. This has an effect on system heat rejection, and hence CoP. Ambient conditions also greatly influence the amount of work required to compress and heat the bleed air. Figure 11 below shows CoP and heat rejection of the system against ambient pressure (proportional to altitude by ISA standards), for the extremes of the flight profile of the aircraft. 


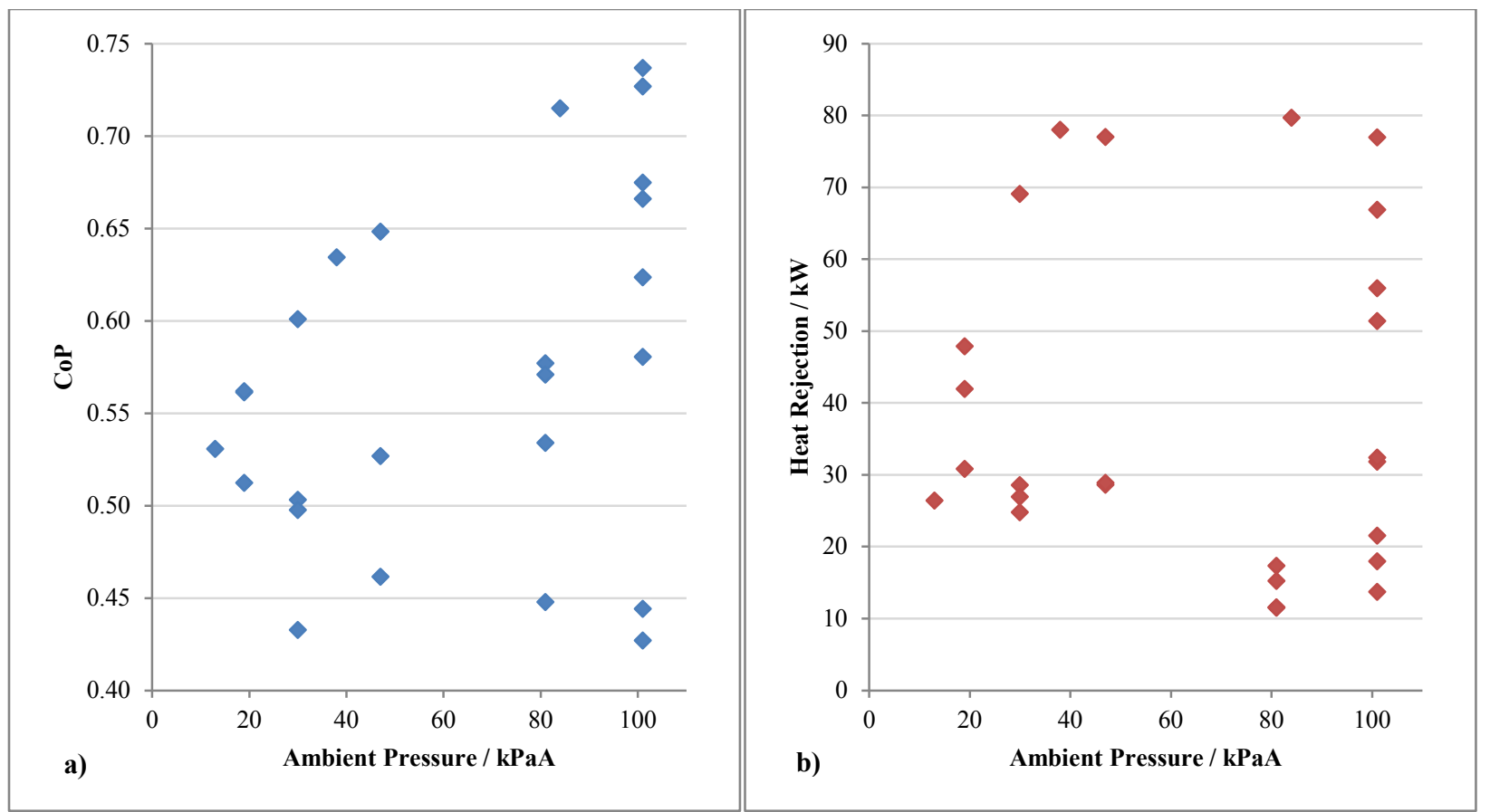

Figure 11. Effects of Ambient Pressure on System Performance

The shape of the flight envelope (shown in Figure 3) can clearly be seen reflected in the plot for CoP. The plot for heat rejection does not show a similar trend. The implication from this is that system performance is not greatly affected by altitude, but efficiency is. This can be attributed to the requirement for more engine compression work. A further investigation could indicate sensible altitude limits for efficient bootstrap cycle operation.

\section{Fault Detection and Isolation (FDI) Application}

\section{A. Real-Case Scenario}

In order to further the capability of the GTF, a scenario was devised that would represent a blocked ram air path on the intercooler. All bleed air inlet conditions and temperature demand settings remain constant, whilst the ram air mass flow is varied.

Figure 12 shows the response of the system in terms of exhaust temperatures and bypass valve positions. As the performance of the intercooler reduces, the turbine exhaust temperature increases. The system then closes the bypass valves to work the cycle harder and reduce the temperature delta between turbine exhaust and cabin supply, in order to maintain the demanded cabin temperature. The system is able to do this up until the point indicated by the vertical dashed line on the graph, where both bypass valves are fully closed. At this point, the system can no longer regulate its output temperature - potentially a dangerous scenario for both the pilot and the aircraft where the emergency ram air case may have to be activated. Equipment temperature control is lost well before this point.

Considering Figure 13, the implication of reduced ram air mass flow is predominantly reduced CoP. This is not in keeping with the earlier observation (Section IV / B) that higher bypass flows always give lower CoP, due to the significantly reduced performance of the refrigeration cycle in this case. CAU shaft power increases with decreasing ram air flow, however the heat rejection from the system falls. The bleed air does a disproportionate amount of work on the CAU when compared to the heat rejection of the system.

The failure does not have to be critical in order to reduce system effectiveness or efficiency - a partial failure would not make itself known to the pilot if the control system was still able to regulate its output to the demanded temperature. 


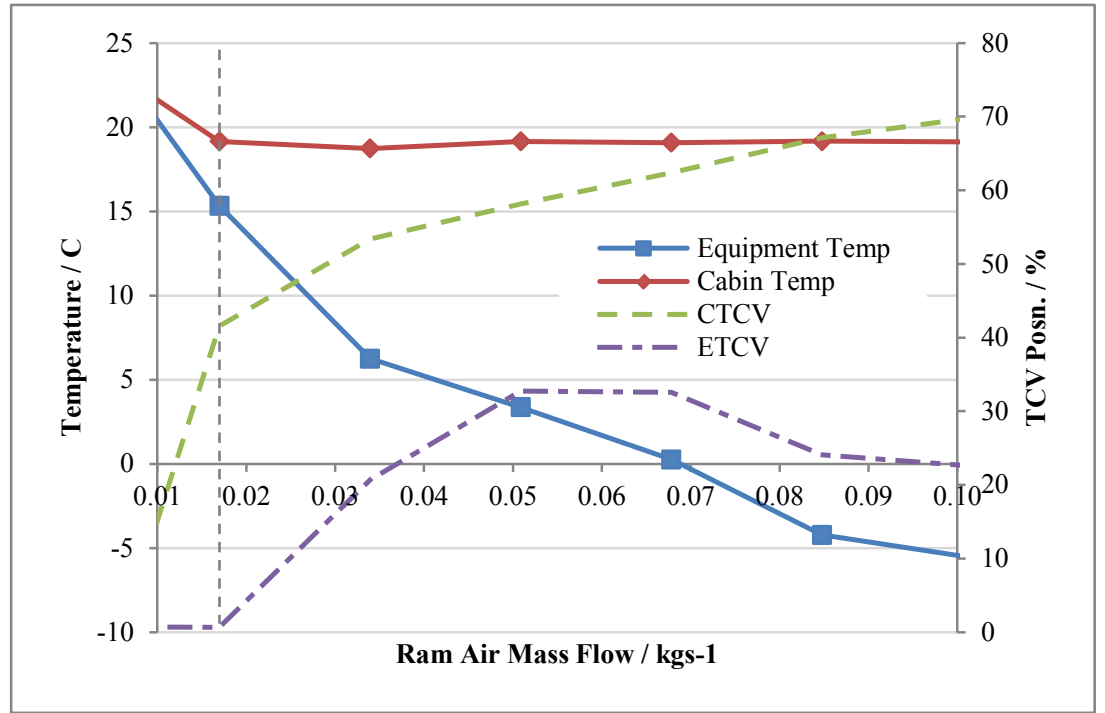

Figure 12. Basic System Response to Ram Air Flow Sweep

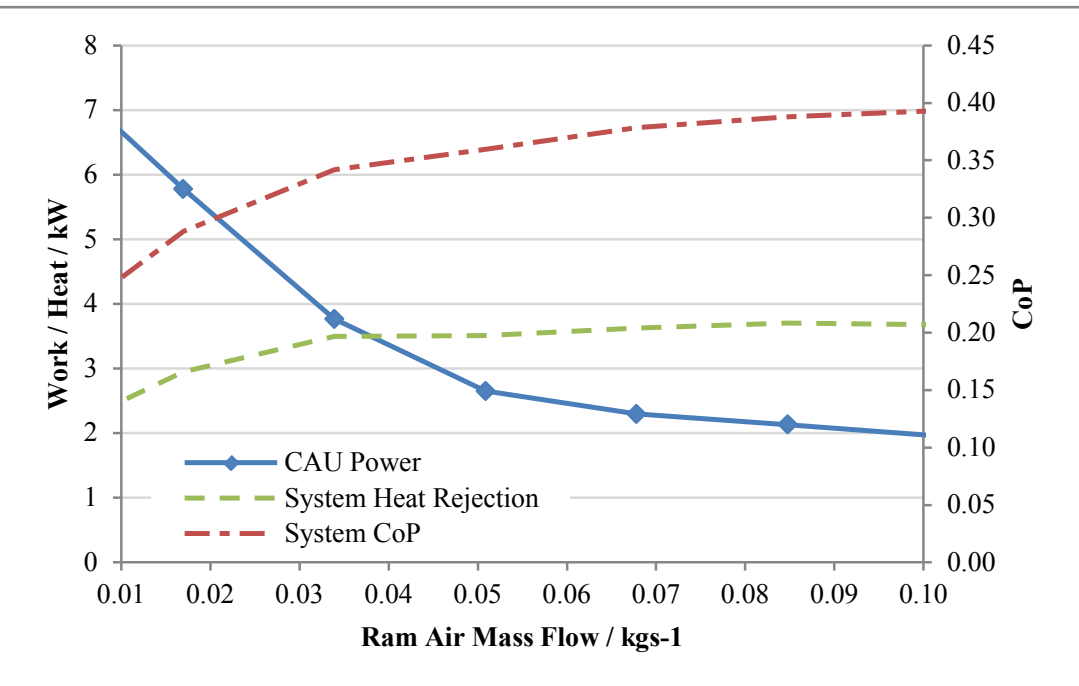

Figure 13. System Energy Analysis for Ram Air Flow Sweep

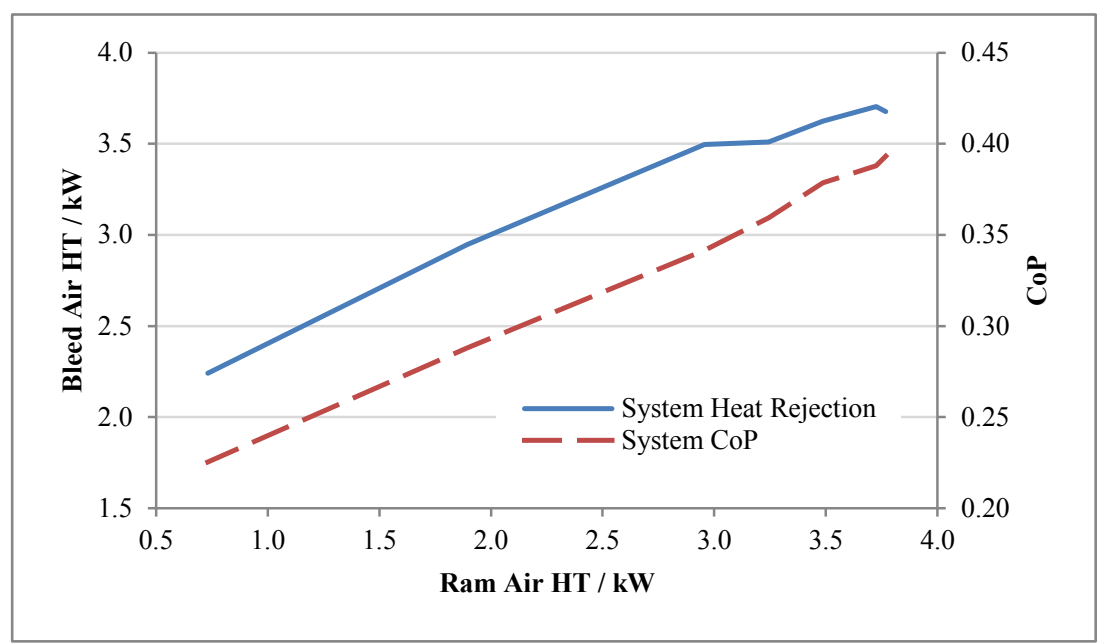

Figure 14. System Performance for Ram Air Heat Transfer
This test demonstrates the value of designing a system that is able to recognise such a failure before it becomes critical. This is especially relevant on more modern aircraft with a high proportion of forced convection cooled avionics. The difficulty arises when considering how wide an operating region the system has to allow for, by design. As Figure 8 shows, a standard 'healthy' operating condition can vary. The nature of the system is complex, and many different states can have the same outcome.

The aim is to use the GTF to trial potential applications of FDI. This would not be practical in either modelled or real-case flight scenarios. The facility allows manipulation of the system, injection of faults, and analysis of the control system in a safe and repeatable environment.

\section{B. Other Test Findings}

Several test results have indicated that ram air flow governs system performance and efficiency. Furthermore Figure 14 shows these two factors plotted against ram air heat transfer. The outcome is a particularly linear response in both cases. This indicates how reliant the system is on ram air flows particularly in the intercooler. System efficiency is largely governed by cycle performance, which in turn is governed by intercooler performance.

When considering CAU power compared to total system heat rejection, it becomes clear that the purpose of the CAU is to serve the intercooler. The CAU provides minimal heat extraction alone. The temperature differential is only achieved through the difference in compression and expansion ratios, and heat lost through the casings. 


\section{Conclusions}

A ground test facility for demonstrating ECS performance was successfully commissioned and installed. This GTF is currently capable of replicating ground operation (APU power) conditions from the donor aircraft. This installation has been proven to operate with sufficient linearity to provide validation data for a $1 \mathrm{D}$ thermodynamic model.

The GTF has been used to implement an initial series of tests for fault detection and isolation purposes, showing how the control system can obscure ECS faults. Similarly, variations in how the control system drives the refrigeration cycle under the same demand and inlet conditions have been witnessed. The system's reliance on intercooler performance has been highlighted.

Planned further work for this facility is to use it as a design tool for future ECS. Investigations will look into FDI, bleed air minimisation and efficiency gains. The intention is to use the GTF to validate modifications made to the design of the ECS in a modelling environment. This will minimise the investment in flight tests, and should ease the transition of technology from design phase to implementation in the aircraft.

\section{Acknowledgements}

The authors wish to thank the Engineering and Physical Sciences Research Council (EPSRC) UK for their support.

\section{Bibliography}

Moir, I., and Seabridge, A., Aircraft Systems: Mechanical, Electrical and Avionics Subsystems Integration, John Wiley \& Sons, 2011.

2 Buckingham, R. D., Helicopter Cooling, Air Cycle/Vapor Cycle Trade-Offs, SAE International, 1984.

3 Rosenbush, F. M., ECS Schemes for All Electric Airliners, SAE International, 1982.

4 Scott, M., Development of a Realistic, Automated, \& Efficient Reliability Development Growth Test for a Large, Distributed, Environmental Control System, SAE International, 1999.

5 Conceição, S. T., Zaparoli, E. L., and Turcio, W. H. L., Thermodynamic Study of Aircraft Air Conditioning Air Cycle Machine: 3-wheel $\times$ 4-wheel, SAE International, 2007.

Ashford, R., and Brown, S., F-22 Environmental Control System/Thermal Management System (ECS/TMS) Flight Test Program - Downloadable Constants, an Innovative Approach, SAE International, 2000.

Tu, Y., and Lin, G. P., "Dynamic Simulation of Aircraft Environmental Control System Based on Flowmaster," Journal of Aircraft, vol. 48, Nov. 2011, pp. 2031-2041.

8 Tu, Y., and Lin, G., "Dynamic Simulation of Humid Air Environmental Control System," 40th International Conference on Environmental Systems, Jul. 2010.

9 Dieckmann, R. R., Improved Reliability and Maintainability for Fighter Aircraft Environmental Control Systems, SAE International, 1988.

10 Ryan, S. K., F-15 Environment Control System Improvements, SAE International, 1990.

11 Rogers, G. F. C., Rogers, G. F. C., and Mayhew, Y. R., Engineering Thermodynamics: Work and Heat Transfer : SI Units, Longman Scientific \& Technical, 1992. 